\title{
SITUACIÓN JURÍDICA DE LOS ANIMALES EN CENTRO AMERICA COMO SERES SINTIENTES ("SENTIENTES BEINGS")
}

Alberto Arguello*

SUMARIO

I. SENTIENCIA ANIMAL, EN LAS LEGISLACIONES ESPECIALES DE NICARAGUA, HONDURAS, EL SALVADOR Y GUATEMALA

II. SENTIENCIA ANIMAL EN EL SALVADOR

III. SENTIENCIA ANIMAL EN LAS LEYES ESPECIALES DE NICARAGUA, HONDURAS Y GUATEMALA

IV. DAÑOS*, AGRAVADOS VERSUS CRUELDAD ANIMAL EN NICARAGUA Y EL SALVADOR

V. SERES SINTIENTES “SENTIENT BEINGS” -O NO-, EN EL CÓDIGO CIVIL DE NICARAGUA Y EL SALVADOR

I. SENTIENCIA ANIMAL, EN LAS LEGISLACIONES ESPECIALES DE NICARAGUA, HONDURAS, EL SALVADOR Y GUATEMALA

Nicaragua fue el segundo país en el año 2010, después de Costa Rica ${ }^{1}$ en 1996 que, comenzó a legislar a favor del Bienestar y Protección de Animales, posteriormente se sumo toda la Región Centroamericana, donde se logra establecer un reconocimiento hacia los animales domésticos y silvestres domesticados, como seres capaces de sentir, percibir y reaccionar, a experiencias negativas y positivas; es decir, un reconocimiento a sus emociones, a la felicidad, o bien a, experimentar el dolor y sufrimiento.

\footnotetext{
${ }^{1}$ No 7451. La Asamblea Legislativa De La Republica De Costa Rica Decreta : Bienestar De Los Animales. 03 Nov 1994
} 
Bajo principio bioético ${ }^{2}$, los ciudadanos de Nicaragua, Honduras, El Salvador Y Guatemala, ahora se encuentran bajo deberes y obligaciones con los de su entorno como "seres vivos", debiendo tener consideraciones morales, deberes y obligaciones, procurando respetar la dignidad, de todo ser vivo que, puede llegar a ser vulnerada; por tanto, el bienestar individual de cada animal cuenta, y la consideración debe encaminar a la sociedad a actuar en beneficio de los seres vivos, bajo la norma moral de dar todo lo que necesiten conforme a los de su especie, como agentes morales y responsables está en juego, puesto que, al estar supeditado un animal a su propietario, éste deberá suministrarle todas las atenciones que demande, por no tener el animal la capacidad de raciocinio, ni de toma de decisiones, en lo concerniente a sus necesidades inmediatas.

Como parte del efecto ante el nuevo cambio legislativo en los países en mención, la sociedad comenzó a incentivarse bajo un nuevo patrón cultural de rechazo a los malos tratos, activándose a favor de mayores denuncias sobre actos crueles e inhumanos hacia los animales; es decir, en el buen sentido de la jerga utilizada en redes sociales, el "Bienestar y Protección de Animales" se ha viralizado de forma radical, en todos los países de Centroamérica, aunque en unos menos y otros más, cada día que pasa, se incrementa una nueva cultura de respeto, moral y bioética, que tiende a incrementarse, ante la tropicalización del nuevo concepto de Bienestar Animal y Protección, ante el reconocimiento del dolor y sufrimiento que sienten los animales.

Estos nuevos conceptos vistos con prudencia y respeto por la sociedad, necesitan reforzarse, al punto que los Ministerio de Educación de cada país, deben de incorporar nuevas políticas educativas en su programas de gobierno, al igual se debe incorporar un exhaustivo estudio del actual ordenamiento normativo, por cada institución tutora de la política pública sobre el bienestar animal, por ser los órganos rectores designados por ley en cada país.

Por la razón antes expuesta, la "Sintiencia Animal", se hace necesaria comprenderla a mayor profundidad, con el fin de readecuar el actual régimen jurídico de los animales, partiendo desde el mismo Código Civil que sigue clasificando a los animales igual a las "cosas", el cual se deriva de las Codificaciones inspiradas en las leyes europeas que influyeron en toda Latinoamerica, partiendo desde el Derecho Romano, que ha sido nuestro ombligo jurídico como fuente histórica, a como lo fue

2 Bienestar Animal, 3oㅡㄹición, Bioética. Patricia Mora Medina 
también el derecho francés, del cual tomamos lo útil, para luego eliminar lo que no se adecuaba a las realidades de nuestros países. Sobre ese justo ordenamiento jurídico, debemos volver a los países influyentes del derecho latinoamericano, para examinar el engranaje normativo que tipifican al dolor y sufrimiento, de los animales domesticados o no, a ser considerados bajo una nueva clasificación como, seres sintientes, o no.

En este sentido, la "Sentiencia Animal", viene a marcar el camino hacia una moderna tendencia jurídica que se encuentra de forma expresa y tácita, en (casi) todas las leyes de protección y bienestar de animales de los países de Guatemala ${ }^{3}$, Honduras ${ }^{4}$, El Salvador ${ }^{5}$ Nicaragua ${ }^{6}$, Costa Rica ${ }^{7}$ y Panamá8; puesto todos han incluido las (5) libertades básica del Bienestar Animal, bajo similitudes legislativas que podemos apreciar claramente la tendencia sobre el régimen de los animales, sin embargo muchas de estas leyes especiales, no han dado el fruto esperado, habiéndose quedados cortas por la falta de voluntad de los gobiernos de turno e incomprensión del termino; sin embargo, se hace necesario auditarnos y valorar indicadores hacia

3 Guatemala: Decreto 05-2017 Ley de Bienestar Animal Guatemala. https://es.scribd.com/document/340551438/Ley-de-Bienestar-Animal

4 Honduras: Ley de Protección y Bienestar Animal, Decreto 115- 2015. http://www.poderjudicial.gob.hn/CEDIJ/Leyes/Documents/Ley\%20de\%20Proteccion\%20y $\% 20 \mathrm{~B}$ ienestar\%20Animal.pdf

${ }^{5}$ El Salvador: Ley De Protección Y Promoción Del Bienestar De Animales De

Ley 330. http://www.asamblea.gob.sv/eparlamento/indice-legislativo/buscador-de-documentoslegislativos/ley-de-proteccion-y-promocion-del-bienestar-de-animales-de-compania

6 Nicaragua: Ley Para La Protección Y Bienestar De Los Animales Domesticó Y Silvestres Domesticados. Ley 747. http://www.poderjudicial.gob.ni/pjupload/spenal/pdf/2010 ley747.pdf

${ }^{7}$ Costa Rica: Reforma a la Ley 7451 de Bienestar de los Animales se aprobó en segundo debate el pasado jueves $1^{\circ}$ de junio del 2017, y fue discutida durante varios meses bajo el proyecto legislativo $\mathrm{N}^{\circ}$ 18.625. Noticia Diario La Nación 01 Junio 2017, Periodista (Alonso Tenorio). http://www.nacion.com/vivir/ambiente/Firman-ley-maltrato-animal 0 1639036121.html

\footnotetext{
8 Panamá: Modificaciones a la ley 70 de 12 de octubre de 2012; De protección de animales domésticos. 10 de Enero del 2017. http://www.asamblea.gob.pa/antproy/2016_A 096.pdf (Diario Noticia, La Estrella, Panamá, Anteproyecto de ley propone multar por maltrato animal; Miércoles 1 de febrero de 2017) http://laestrella.com.pa/panama/nacional/anteproyecto-propone-multarmaltrato-animal/23984079
} 
la Sintiencia Animal; por ejemplo, examinar al país de El Salvador, que ha mostrado inconformidades en su nueva ley especial se hace valedero valorar e indentificar las formas de registrar, el dolor y sufrimiento animal.

\section{SENTIENCIA ANIMAL EN EL SALVADOR}

El país de El Salvador, ha llamado la atención en los medios de comunicación internacional y nacional que concentro la ley de protección animal únicamente para los animales de compañía, hecho que a lo inmediato generó un gran vacío jurídico, e interrogante por los fuertes índices de violencia que se registran por el fenómeno de las maras y, al enfocarse solo en mascotas, aisla el espacio idóneo para lo no alcanzado por el Código Penal, puesto también el código, solo aplica únicamente para aquellos delitos que son "relativos a la naturaleza y el medio ambiente9; en ambas leyes, especial y código penal, se aprecia un vacío jurídico de protección animal ante el reclamo social sobre hechos que extremecen a los salvadoreños, como por ejemplo, el ataque que sufrió el "hipopotamo Gustavito" en el Zoológico Salvadoreño, que fue cruelmente atacado por un grupo de personas que utilizaron diversos objetos punzocortantes y contundentes que le causaron graves heridas en su cuerpo hasta ocasionarle la muerte ${ }^{10}$. El acto cruel hacia Gustavito demostró y dejo evidencia, a una débil y obsoleta legislación penal y a una ley bienestar animal de bajo alcance, que a lo inmediato no contribuye con la política de bienestar y protección a los animales en el país salvadoreño. A continuación, comparto el articulo número (4) de la Ley De Protección Y Promoción Del Bienestar De Animales

\footnotetext{
${ }^{9}$ Decreto 1030 Código Penal El Salvador. Capitulo II De Los Delitos Relativos A La Naturaleza Y El Medio Ambiente Depredación De Fauna. Art. 260.- El que empleare para la caza o la pesca veneno, medios explosivos u otros instrumentos o artes susceptibles de generar una eficacia destructiva semejante, será sancionado con prisión de uno a tres años. (3) Depredación De Fauna Protegida Art. 261.- El que cazare o pescare especies amenazadas, realizare actividades que impidieren 0 dificultaren su reproducción o contraviniendo las leyes o reglamentos protectores de las especies de fauna silvestre, comerciare con las mismas o con sus restos, será sancionado con prisión de tres a cinco años. La sanción se aumentará en un tercio del máximo de lo señalado en el inciso anterior, si se tratare de especies catalogadas en peligro de extinción.
}

10 La Prensa Grafica. "GUSTAVITO", EL HIPOPÓTAMO DEL ZOO NACIONAL, MUERE POR UNA GOLPIZAhttp://www.laprensagrafica.com/2017/02/27/muere-gustavito-el-hipopotamo-delzoologico-nacional 
De Ley 330, que de forma clara y precisa, describe a los perros, gatos, como animales de compañía y no como "Seres Sentientes".

Ley 330* Art. 4(b) : Animales de compañía: perros, gatos u otros animales domésticos adquiridos para dar compañía a su propietario, poseedor o tenedor, que los mantiene generalmente en su hogar $y$ comúnmente se denominan también como "mascotas"

\section{SENTIENCIA ANIMAL EN LAS LEYES ESPECIALES DE NICARAGUA, HONDURAS Y GUATEMALA}

Los países de Nicaragua, Honduras y Guatemala, presentan conceptualizaciones a fines en sus leyes especiales en lo que respecta a la "Sintiencia Animal", en cuanto a la terminología usa para definir a los "Animales", y de igual forma muestran garantías de protección implícitas de forma similar. Sin embargo, Guatemala usa una terminología más puntual, bajo una estructura más amplia y acorde a al reconocimiento para los animales como "seres Sintientes", término comprendido en la ley, visto bajo una fácil compresión y lectura que facilita la ruta jurídica sobre la tendencia trazada hacia la consideración de la sintiencia de los animales, a como vemos a continuación, iniciando por el país de Nicaragua y finalizando por Guatemala:

* Nicaragua: Definición de Animal: Art. 10 Para los efectos de esta Ley,

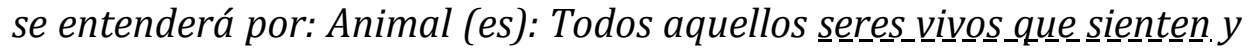
se mueven por su propio impulso, pero que se diferencian de los seres humanos por la falta de razón

* Honduras: Definiciones Animal: Art. 2 Cualquier mamífero no humano,

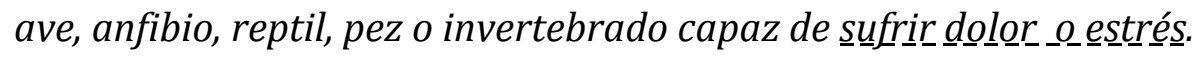

Guatemala: Objeto:

Art. 2 La Presente Ley tiene por objeto crear las regulaciones necesarias para la protección y el bienestar de los animales, debiendo por ello ser cuidadosos sin 
detrimento de su condición de seres vivos. Los principios sobre los que se emite la presente ley son los siguientes:

a) Todos los animales tendrán a partir de la promulgación de la presente ley, el

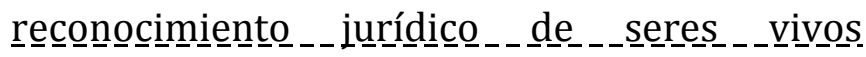
sintiententes y contaran con especial protección contra el sufrimiento y el dolor causados directa o indirectamente por los seres humanos.

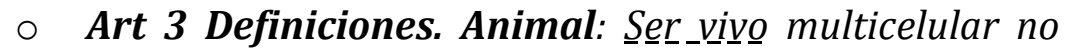
humano que presenta un sistema nervioso ca $\underline{a} \underline{p} \underline{a} \underline{z}$ de sesentir doloror responder a los estímulos y moverse voluntariamente.

Según pudimos apreciar, el compromiso de cada país quedó definido en el espíritu de sus leyes especiales y ellos deberán de poner en uso, tarde o temprano, sus normas regulatorias, puesto el espíritu jurídico de cada una, define a los animales, hacia la consideración de la "Sintiencia Animal"; por tanto, estas nuevas regulaciones como efectos de futuros en la sociedad, deberán transcender e impactar otros instituciones y poderes de estado de cada país, presión que de forma automática surgirá hacia otras leyes que impliquen animales.

\section{DAÑOS*, AGRAVADOS VERSUS CRUELDAD ANIMAL EN NICARAGUA Y EL SALVADOR}

Los países examinados, no deben sosegarse únicamente a las leyes especiales, dado a que la falta de reglamentaciones de ellas puede paralizar la eficacia de interés y objeto de las leyes, sobre esto me refiero a la realidad de Nicaragua, puesto que aceptar el dolor y sufrimiento causado a los animales por el hombre, no debe ser visto por los gobiernos sin una visión de nación; es decir, la ley 747 de Nicaragua, fue inspiradas en el proyecto de la DUBA (Declaración Universal de Bienestar Animal) y la falta de visión de gobierno, trunco el proceso de desarrollo institucional, lo que ha generado un rechazo social por la falta de reglamentación, por el incumplimiento de la norma. También podemos poner otro ejemplo en el país de el Salvador, que se inspira en la Declaración Universal De Los Derecho De Los Animales, la cual indica que, todos los animales nacen de forma igual en el mundo, 
sin embargo la realidad país fue, que la ley 330 solo aplica a las mascotas, en este aspecto, en ambos países se aprecia una ineficiente estructura jurídica por falta de visión país; y estas inadecuación a las normas de derecho positivo vigente, generan deficiencias al sistema actual, dificultando el régimen legal de protección a los animales; por ejemplo, considerar modificaciones de reformas hacia tipificaciones más modernas de anti crueldad ${ }^{11}$, es algo deseado, ya que puede prevenirse a una sociedad de actos violentos, pero cegarnos a la "sintiencia animal" como país, es persistir a que en los Códigos Penales como el caso de Nicaragua (Art: 391) se sigan exceptuando las peleas de gallos y corridas de toros fuera de la clasificación de maltrato animal pero sí, dentro de los delitos de daños agravados a la propiedad; y, definitivamente, esto no contribuyen a erradicar el dolor y sufrimiento, ni a experimentar nuevos cambios de conductas sociales y de ser así, no se estaría reconociendo al bienestar animal como una política universal y emergente en la comunidad internacional, (Sabine BRELS, May 2012, derechoanimal.info), puesto todas estas leyes surgen por compromisos internacionales y reconocimiento a los (5) estándares de libertad sobre el bienestar animal.

Sobre este enfoque, deseo subrayar mostrando el sigueinte ejemplo: Una gallo de pelea que es consentido, criado, entrenado, bien alimentado y asistido en salud animal, por los mejores veterinarios, para ser todo un campeón, valorado en U\$5,000.00 y (+), cuyo fin será la muerte de forma cruel, por placer gallero; conforme al Código Penal de Nicaragua, no es sujeto de derecho de protección por maltrato y sometimiento crueles, pero sí puede ser exigible el derecho del propietario por "daños agravados" en materia penal, por destruirlo, desaparecerlo o causarle de cualquier modo, daño, por ser un bien mueble, total o parcialmente por alguien ajeno. Así mismo, puede exigir por la vía civil, la Mala Praxis, al incurrir en una negligencia o culpa del médico veterinario, pero no, por maltrato animal. Esto demuestra una rotunda deficiencia en el sistema legal, al actual régimen jurídico de los animales, donde se merece examinar nuevamente el código penal y adecuarlo hacia la realidad social, tomando una verdadera conciencia hacia la "sientiencia animal", sobre una visión normativa moral y ética coherente como política de estado, para extraer a los animales de la tipificación en los Códigos Penales bajo el delitos de daños agravados, o daños a como se muestra en el Código Penal Salvadoreño, por considerárseles "bienes muebles"; justa causa para reclasificarlos bajo delitos por maltrato puro, por cometer en su contra, actos crueles y violentos.

\footnotetext{
11 An introduction to Animal Law. Joan E. Schaffner. The future: Animal as Subjects. Pg 171- 175
} 


\section{SERES SINTIENTES “SENTIENT BEINGS” -0 NO-, EN EL CÓDIGO CIVIL DE NICARAGUA Y EL SALVADOR}

En Nicaragua y El Salvador, la tipificación por delitos sobre daños a los bienes muebles en propiedad privada en materia penal, se vinculan por la clasificación a los animales en el códigos civiles como bienes muebles, igual a las cosas, es decir, bajo el Código Civil, a los animales no se les considera Seres Sintientes "Sentient Beings" a como lo veremos en los artículos penales y civiles a continuación :

\section{Código Penal de Nicaragua CAPÍTULO VIII DE LOS DAÑOS}

- Art. 243 Daño : Quien destruya, inutilice, haga desaparecer o de cualquier modo dañe un bien_ $\underline{\text { mueble }}$ o inmueble, total o parcialmente ajeno, siempre que el hecho no constituya otro delito más severamente penado, será sancionado con prisión de seis meses a dos años o de noventa a trescientos días multa o trabajo en beneficio de la comunidad de cuarenta y cinco a doscientos días de dos horas diarias, atendida la condición económica de la víctima y la cuantía del daño, si éste excediera de dos salarios mínimos mensuales del sector industrial.

- Art 244 Daño agravado: Se impondrá prisión de dos a tres años cuando el daño: Inciso g) Produzca infección o contagio en plantas o_annimal $\underline{\text { les }}$;

Código Penal De El Salvador : Daños

- Art. 221 DAÑOS - El que con el propósito de ocasionar perjuicio destruyere, inutilizare, hiciere desaparecer o deteriorare una cosa total o parcialmente ajena, siempre que el daño excediere de doscientos colones, será sancionado con prisión de seis meses a dos años. 


\section{dA derecho ANIMAL la web center de los animales con derecho}

- En igual sanción incurrirán los individuos que dañen bienes muebles o inmuebles, públicos o privados, mediante cualquier inscripción de palabras, figuras, símbolos o marcas fueren estos grabados o pintados.

Los Códigos de Nicaragua y El Salvador fueron ambos influenciados, por el Código Civil Chileno y, el Chileno por el Francés, por tal motivo las codificaciones con respecto a la clasificación de los animales en el libro de propiedades y bienes muebles, fueren casi exactas en todos los países que se influyeron por el Derecho Romano, Francés y Chileno hasta llegar a la primera edición del Código Civil de Nicaragua que fue aprobado por la Cámara del Senado el 19 de marzo de 1866 y el 25 de enero de 1867, concluyendo con una tercer y última edición en 1931 ${ }^{12}$, definiendo el estatus jurídico a los animales en el Tomo II de la Propiedad, Bienes, a como los demostramos en los artículos a continuación.

\section{Código Civil de Nicaragua:}

- Arto. 597.- Los bienes consisten en cosas que jurídicamente son muebles inmuebles.

- Arto. 666.- Los animales domésticos están sujetos a dominio que se adquiere y trasmite en la misma forma que las demás cosas.

Igual mente el Código Civil de El Salvador se alimento del francés para el tiraje de su primera edición el 23 de marzo del año 1857, quedando los animales de igual forma en el libro de la propiedad, a como lo muestro a continuación:

Código Civil De El Salvador :

- Art. 560.- Se llaman bienes todas las cosas que son o pueden ser objeto de apropiación, y se dividen en inmuebles y muebles

- Art. 568.- Se llama dominio o propiedad el derecho de poseer exclusivamente una cosa y gozar y disponer de ella, sin más

\footnotetext{
${ }^{12}$ Antecedente Histórico del Código Civil de Nicaragua. Dirección General del Digesto Jurídico Nicaragüense. Nicaragua, Febrero 2016.http://digesto.asamblea.gob.ni/wpcontent/uploads/2016/02/historia-codigo-civil.pdfç
} 


\section{dA derecho ANIMAL la web center de los animales con derecho}

limitaciones que las establecidas por la ley o por la voluntad del propietario.

- Art. 604.- Los animales domésticos están sujetos a dominio.

Si tuviésemos que valorar a la Sintiencia Animal como un indicador, los códigos civiles de ambos países, presentan regímenes jurídicos de propiedad obsoletos, ${ }^{13}$ con respecto a la clasificación de los animales al igual que las cosas, sin embargo todo esto se origino, sobre base de un valor económico que representaban los animales como bienes agrícolas semovientes, y fue el régimen jurídico que se constituyó, a como indica Contreras ${ }^{14}$, en la era de la codificación latinoamericana de las Repúblicas-, en los siglos XIX y XX.

Hoy nos enfrentamos ante nuevas consideraciones modernas con respecto a los animales bajo la consideración de Seres Sintientes ("Sentient Beings") que han dejado de ser vistos al igual que las demás cosas, y a pesar que los animales son propiedad de los seres humanos y que están bajo las leyes de la propiedad para fines y propósitos diferentes, la tendencia marca y apunta a ser visto bajo otra clasificación jurídica, término que viene ganando terreno y es el concepto que ha transformado las políticas Europeas ${ }^{15}$ en materia de agricultura, pesca, transporte, mercado interior,investigación, desarrollo tecnológico y espacio, teniendo plenamente en cuenta la Unión y los Estados miembros, nuevas exigencias en materia de bienestar de los animales como seres sensibles.

La sociedad europea bajo este nuevo concepto, como resultado del TFUE (Tratado de Funcionamiento de la Unión Europea) es consciente que, debe reconocer emociones, sufrimientos y bienestar a los animales, evitándoles, (dolor, temor, angustia o frustración), por tanto, conceder una nueva clasificación de estatus jurídico, es en respuesta a la misma sociedad, y como tal, deberá aplicarse a todos los animales por igual ${ }^{16}$.

13 Teresa Giménez-Candela. La Descosificación de los animales (I). 2017.03.02

${ }^{14}$ Carlos Andrés Contreras López. 2016. Régimen Jurídico De Los Animales En Chile, Colombia Y Argentina. (II Códigos Civiles Latinoamericanos A. El Proceso De Codificación En Latinoamérica) Pg. 39; (Código Civil Chileno) Pg. 49. Tirant Lo Blanch. lxxix DECRETO por el que se promulga el Código Civil de 1904; José Santos Zelaya; Managua 1o de Febrero 1904.

${ }^{15}$ Animales y Derecho. Teresa Gimenez-Candela \& David Favre. TFUE artículo 13. Enrique Alonso.

${ }^{16}$ Declaración Universal de los Derecho del Animal, Art 1. Todos los animales nacen iguales ante la vida, y tiene los mismos derechos a la existencia. 
La trascendencia y adecuación sobre el TFUE17 conforme al artículo 13, que entro en vigor el $1^{\text {o }}$ de Diciembre del 2009, provoco en en el Código Civil Francés que, no hacia enmiendas desde 1804, cambios al régimen de los animales de la categoría de"bienes muebles" al reconocimiento de la sintiencia animal en marzo del año 2015.

El famoso Código Napoleónico, dio giro radical hacia un nuevo régimen jurídico a favor de los animales, modernizadose hacia la nueva clasificación de "seres vivos dotados de sentiencia18" (êtres vivants doués de sensibilité)", cambio que debe impactar de forma horizontal, a todos los países que se inspiraron en su codificación civil.

Otra reforma de trascendencia jurídica a favor de los animales en Sudamérica, ha ocurrido en Colombia ${ }^{19}$, donde se ha aprobado el Proyecto de Ley número 1774 del 06 de Enero 2016, por medio del cual se reforma el Código civil, el Código Penal y el de Procedimiento Penal, cediendo a los animales la consideración a los animales como seres sintientes quedando de la siguiente forma.

"EL CONGRESO DE COLOMBIA DECRETA: Art1. Objeto. Los animales como seres sintientes no son cosas, recibirán especial protección contra el sufrimiento y el dolor, en especial, el causado directa o indirectamente por los humanos, por lo cual en la presente ley se tipifican como punibles algunas conductas relacionadas con el maltrato a los animales, y se establece un procedimiento sancionatorio de carácter policivo y judicial."

\footnotetext{
17 El articulo 13 Tratado de Funcionamiento de la Unión Europea. Los animales como seres “ sensibles"( sintientes) a la luz de la jurisprudencia del Tribunal de Justicia de la Union Europea. Enrique Alonso. Libro Animales y Derecho . T Gimenez-Candela

${ }^{18}$ El Derecho Animal en 2015. Teresa Giménez-Candela.

${ }^{19}$ Colombia. Ley 1774, 06 de Enero 2016.

http://es.presidencia.gov.co/normativa/normativa/LEY\%201774\%20DEL\%206\%20DE\%20ENER 0\%20DE\%202016.pdf
} 


\section{dA derecho ANIMAL la web center de los animales con derecho}

Por tanto, ante los últimos acontecimientos ocurridos, no debemos menospreciar la tendencia jurídica de inclusión a los animales como "seres sintientes" en los Códigos Civiles de Centro América, puesto ya hemos dado los primeros pasos con leyes especiales, sin embargo la visión de país, es demanda un compromiso mayor, moral y éticamente, puesto hemos venido por muchos años desplazando y explotando a los animales de forma inhumana. Sobre el anhelo de muchos estudiosos del Derecho Animal deseo concluir compartiendo las palabras de la Catedrática de la UAB, Directora del Master en Derecho Animal \& Sociedad, Teresa Giménez-Candela, "Animalizarnos nosotros un poco, no haría nada mal ". Expresión que la debemos aplicar a nuestras legislaciones de Centro América, igual creo que no nos haría nada mal, promover un cambio de régimen más acertado para los animales. 